Instituto Internacional de Investigación y Desarrollo Tecnológico Educativo INDTEC, C.A.

DOI: https://doi.org/10.29394/Scientific.issn.2542-2987.2020.5.16.14.269-289

OAI-PMH: http://www.indteca.com/ojs/index.php/Revista Scientific/oai

Ensayo Original / Original Essay

\title{
Hologogía Educativa: Espirales Hologógicos de la Visión del Docente en la Educación Primaria
}

\author{
Autor: César Enrique López Arrillaga \\ Unidad Educativa Nacional Bolivariana Guaicaipuro, UENBG \\ prof.cesarlopez@gmail.com \\ Caracas, Venezuela \\ https://orcid.org/0000-0002-2926-8508
}

Resumen

La Hologogía Educativa promueve planteamientos teóricos de elementos que integran la Visión del Docente en la Educación Primaria bajo las premisas de la Hologogía, concebida en las posturas de Barrera (2013); la Autonomía de la Educación postulada por Freire (1977); la Educación Holística descrita por Gallegos (2003): que permiten considerar el proceso de enseñanza-aprendizaje con tendencia hologógica, espiritual, holística concatenada con la Visión del Docente en materialización de una praxis integral que considere a los estudiantes como holos para consolidar la formación holística que surja de su personalidad (mente, cuerpo, espíritu y alma), con la aplicación de acciones y estrategias pedagógicas y cognitivas en los ambientes de aprendizajes, igualmente fundamentado en la promoción de los principios de la Visión Hologógica del Docente, para lograr la consolidación de una educación que desarrolle procesos continuos de construcción del conocimiento e impulsar la sociedad planetaria.

Palabras clave: educación; educación integradora; docente de escuela primaria.

Cómo citar este ensayo:

López, C. (2020). Hologogía Educativa: Espirales Hologógicos de la Visión del Docente en la Educación Primaria. Revista Scientific, 5(16), 269-289, e-ISSN: 2542-2987. Recuperado de: https://doi.org/10.29394/Scientific.issn.2542-2987.2020.5.16.14.269-289

Fecha de Recepción: 16-12-2019
Fecha de Aceptación:

14-03-2020
Fecha de Publicación:

05-05-2020 


\title{
Educational Hologogy: Holographic Spirals of the Teacher's Vision in Primary Education
}

\begin{abstract}
The Educational Hologogy promotes theoretical approaches of elements that integrate the Vision of the Teacher in Primary Education under the premises of the Hologogy, conceived in the positions of Barrera (2013); the Autonomy of Education postulated by Freire (1977); Holistic Education described by Gallegos (2003): that allow to consider the teaching-learning process with a holographic, spiritual, holistic tendency concatenated with the Teacher's Vision in materialization of a comprehensive praxis that considers students as holos to consolidate holistic training that arises from their personality (mind, body, spirit and soul), with the application of pedagogical and cognitive actions and strategies in learning environments, also based on the promotion of the principles of the Teacher's Holographic Vision, to achieve consolidation of an education that develops continuous processes of knowledge construction and promote planetary society.
\end{abstract}

Keywords: education; inclusive education; primary school teacher.

How to cite this essay:

López, C. (2020). Educational Hologogy: Holographic Spirals of the Teacher's Vision in Primary Education. Revista Scientific, 5(16), 269-289, e-ISSN: 2542-2987. Recovered from: https://doi.org/10.29394/Scientific.issn.2542-2987.2020.5.16.14.269-289

Date Received:

16-12-2019
Date Acceptance:

14-03-2020
Date Publication: 05-05-2020 


\section{Introducción}

En la actualidad se observa en la educación primaria que manifiesta una desmejora en las concepciones y desempeño de los actores del quehacer educativo en función del proceso de enseñanza y aprendizaje desde una visión mecánica con acciones de solo transmitir conocimiento al estudiante, mediante la memorización de contenidos, programas en el marco de currículo desvinculado de la realidad y diversidad social de los educandos. En este contexto, se visualiza una tendencia educativa tradicionalista que no permite superar las barreras actuales, se encuentra sumergida en una crisis derivada por la globalización en los niveles de una economía que afecta a las políticas públicas educativas de Venezuela, teniendo incidencia en las instituciones educativas en especial al desempeño los profesionales de la educación primaria.

Al respecto, la hologogía permite que la educación se transforme a un proceso continuo, abierto y flexible en el cual el estudiante es el centro de la acción educativa, en la promoción de la educación holística para el amor, la tolerancia, humanista en el marco de la dignidad humana de los educandos desde su diversidad, particularidades e intereses, es reconocer a cada uno desde sus holos, sus etapas de desarrollo y singular construcción e intercambio de saberes y conocimiento, es transcender a una formación espiritual desde la humanidad de los actores del hecho educativo.

En este orden de ideas, la Hologogía se orienta a identificar y reconocer a los estudiantes desde su integralidad como personas humanas en un proceso educativo para seres humanos desde la colectividad con elementos que pueden elevar la visión y labor educativo de los docentes en el hecho educativo que corresponda a los holos de cada educando en formación. En consecuencia, los docentes se relacionan con los estudiantes desde sus aspectos sociales, psicológicos, emocionales y cognitivos desde los procesos de aprendizajes desde la diversidad en el entorno escolar. 
Dentro de este marco, la hologogía se orienta a la integración de todos los aspectos de los seres humanos en su proceso de formación y aprendizaje, por lo cual la visión hologógica de los docentes se materializa con la interpretación, valoración de los estudiantes desde su diversidad compleja en los aspectos y dimensiones como únicos, complejos en la diversidad de personalidades que existe en el contexto escolar. Las afirmaciones anteriores sugieren que, la hologogía es humanizar los procesos educativos.

\section{Hologogía Educativa: Espirales Hologógicos desde la concepción de los docentes}

La concepción hologógica del docente en su praxis educativa en los ambientes de aprendizaje se orienta a los educandos, para satisfacer sus necesidades e intereses de formación, orientada a la consolidación de los aspectos cognitivos, siempre he reconocido que cada estudiante es una individualidad que posee actitudes y realidades propias, así como sus intereses. Aunado a esto, la educación es el proceso que permite interacciones y transformación, en relación con lo anterior, Barrera (2013a), expresa que: "la educación también debe ser vista desde el virtualismo ya que participa de la condición también potencial del ser humano -principio, centro y fin de la actividad educativo" (pág. 26).

En tal sentido, la hologogía se encuentra orientada en realizar las transformaciones de los procesos educativos en una visión integral de los estudiantes como seres humanos en permanente evolución, con actitudes propias y complejas, por ello, se reconoce que cada etapa de vida debe ajustar la educación para permitir una formación holística e integral, en tal sentido surge una visión hologógica de la docente centrada a los educandos desde su dignidad humana. Partiendo de tales preámbulos, surge la Visión Hologógica del Docente en el Contexto de la Educación Primaria, cuya estructura en el espiral holístico, se ilustra en la figura 1. 


\section{Ensayo Original / Original Essay}

Figura 1. Espiral Hologógico: Visión Hologógica del Docente.

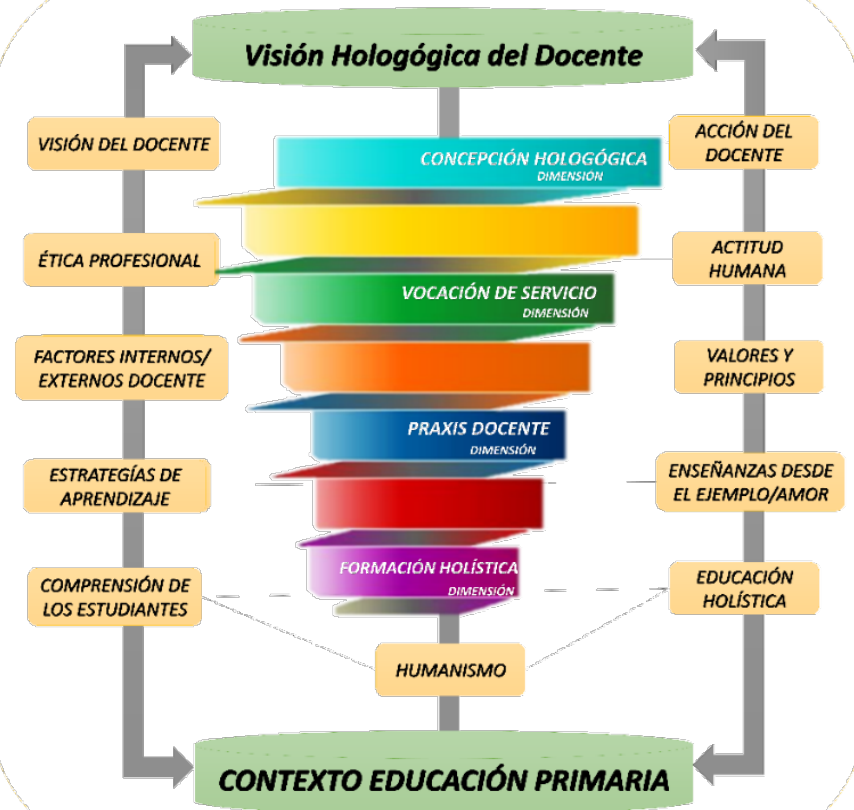

Fuente: El Autor (2019).

En efecto, en el anterior espiral Hologógico se presenta la Visión Hologógica del Docente estructurada en cuatro dimensiones develadas por la práctica de los profesionales, las cuales son: Concepción Hologógica del Docente; Vocación de Servicio, Praxis Docente y Formación Holística, la cuales se desarrollan en el espiral Hologógico interactuando continuamente en el espiral cíclico continuo e infinito, con los elementos que la conforman: Visión del Docente, Acción del Docente, Ética Profesional, Actitud Humana, Factores Internos-Externos Docente, Valores y Principios, Aspectos Cognitivos, Humanismo, Estrategias de Aprendizajes, Educación Holística, Comprensión de las necesidades de los estudiantes, Enseñanzas desde el ejemplo y amor, las cuales manifiestan de forma continua y permanente, en las dimensiones. Al respecto, Gallegos (2003):

La visión holista emergente incluye una nueva ciencia y una 
nueva espiritualidad, ambas basadas en una nueva comprensión del universo que habitamos y de quiénes somos. La nueva visión ya no confunde ciencia y espiritualidad como en el paradigma dogmático, ni las separa como en el paradigma científico, sino que las integra en un marco ampliado de la experiencia humana (pág. 106).

En tal sentido, dentro de los elementos se encuentra la Visión del Docente fundamentada por la percepción de los docentes en cuanto a su misión educativa en el quehacer educativa orientada a las políticas públicas educativas, orientaciones pedagógicas en el marco de satisfacer las necesidades de los estudiantes en la diversidad reconociéndolos como seres humanos en formación holística, considerando la educación desde la praxis hologógica. Al respecto, Barrera (2013b), desde la visión holística: "permite entender los eventos desde el punto de vista de las múltiples interacciones que los caracterizan, corresponde a una condición interpretativa orientada hacia la comprensión integral de los procesos, de los protagonistas y de su contexto" (pág. 12). Por lo tanto, la Acción del Docente es el actuar cotidiano del profesional de la docencia en sus relaciones con los estudiantes orientado a reconocerlos como seres humanos en los valores del buen trato, la tolerancia, la ternura, amoroso y la comprensión de las debilidades de sus educandos en su dignidad como ciudadanos.

Asimismo, la Ética Profesional surge como el deber ser de los profesionales de educación en cuanto al cumplimiento de su labor educativa bajo los principios y valores éticos morales, con el propósito de realizar con dedicación, esmero, con sentimientos para la satisfacción del deber cumplido, propiciando un ambiente agradable a los estudiantes desde las buenas prácticas educativos para fortalecer un ámbito cognitivo e intelectual. En concordancia, para Rojas (2011): "la ética general es aquella que se refiere a los principios universales del actuar humano (valores, diferencia entre bien y mal, libertad, responsabilidad, acto humano)" (pág. 6). En tal sentido, los 
docentes en el contexto de educación primaria en su praxis educativa se orientan a identificar la diferencia de lo que está bien o está mal, para garantizar la dignidad humana en los principios y valores universales de los seres humanos y sus relaciones sociales.

Es así como, la Actitud Humana desde las intencionalidades del docente como ser humano posee actitudes propias que se realizan en el contexto educativo, desempeñando el papel educadores, así mismo, las cuales nos conlleva a la actitud humana que se realiza con la ética bajo la premisa que el actuar de los profesionales de la docencia va dirigido en el marco de los valores humanos para impulsar, resguardar la integridad de principios, personalidad, intereses, cultura, credo, ideología, espiritual y creencias de los estudiantes, respetar los principios humanos de todos en el quehacer educativo. Relacionado con lo anterior, es importante desatacar lo planteado por Huerta (2008): "la actitud es un lenguaje universal” (pág. 14).

En efecto, los Factores Internos-Externos Docente hace referencia al contexto externo como la comunidad, estudiantes, representantes, familias entre otros, además, el interior hacer referencia a su personalidad y procesamiento de los pensamientos, sentimiento y voluntad propia, todas ellas inciden en su praxis educativa. Debido a esto, el docente en el contexto de educación primaria se encuentra relacionado con vivencias y experiencias en continuo desarrollo para su aprendizaje propio, las cuales en algunas ocasiones afectan su desempeño como educadores, sin embargo, prevalece la fuerza de voluntad y el ánimo de hacer la labor educativa.

Así pues, los Valores y Principios son el conjunto de acciones positivas que moldean las conductas de los estudiantes a través del ejemplo de los docentes en el contexto de educación primaria, es entonces, importante la aplicación de los valores en el quehacer educativo, para el forjamiento de buenos ciudadanos con la consolidación de los estudiantes en su personalidad integral y holística para ser productos en la sociedad actual. 
Dentro de este marco, el Humanismo es un elemento esencial para el proceso educativo, la forma de humanizar la educación orientada para los seres humanos, el docente de educación primaria reconoce al estudiante como seres humanos y prevalece en el quehacer educativo la dignidad humana en el marco de la tolerancia, solidaridad, valores, buen trato, respeto y comunicación efectiva entre todos los participantes del contexto escolar. Es por esta razón que, las Estrategias de Aprendizajes referidas a las planificaciones de los docentes en el contexto de educación primaria, es el camino pedagógico que establece las acciones en función de propiciar los aprendizajes en los estudiantes, de allí que, se orienta a la visión del educador posea y perciba de la educación. En consecuencia, se destaca lo planteado por Freire (1993):

Se van dando de tal manera que, por un lado, quien enseña aprende al enseñar porque reconoce un conocimiento antes aprendido y, por el otro, porque observando la manera como la curiosidad del alumno aprendiz trabaja para aprehender lo que se le está enseñando, sino lo cual no aprende, el educador ayuda a descubrir dudas, aciertos y errores (pág. 28).

De acuerdo a las apreciaciones anteriores, en las estrategias de aprendizajes el docente juega un papel colaborador y mediador de los procesos de enseñando aprendiendo, coadyuvando a los estudiantes en su formación integral en el marco de la hologogía. En este orden de ideas, la Educación Holística es desarrollar un modelo de educación que reconoce a los estudiantes como holos con el significado de entero, completo, todo, además, se puede conceptualizar como integro u organizado, partiendo de los holos la educación holística como elemento de la Visión Hologógica del Docente es un proceso de comprensión de la totalidad y complejidad de los estudiantes únicos que expresan en el hecho educativo múltiples relaciones en una comprensión integradora en el contexto de educación primaria. Aunado a esto, Barrera (2013c), puntualiza sobre la holística: 
La holística es una tendencia que permite entender los eventos desde el punto de vista de las múltiples interacciones que los caracterizan; corresponde a una condición interpretativa orientada hacia la comprensión integral de los procesos, de los protagonistas y de sus contextos (pág. 12).

Es importante resaltar que desde la visión de los docentes se ubica el conocimiento de la unicidad e integralidad de los estudiantes en formación en el marco de la dignidad humana. Se hace necesario resaltar, la Comprensión de la Diversidad de los Estudiantes es la actitud desarrollada por los docentes de la educación primaria en cuanto a identificar, valorar y comprender desde la complejidad, diversidad de los estudiantes como holos, es decir, íntegros, únicos y complejos desde la diversidad de hechos, realidades con caracteres distintos en el proceso de aprendizaje y enseñanza, por lo cual, prescribe en tener la capacidad de realizar acciones en función de la tolerancia y aceptación, valorando a los educandos como seres humanos centrando la visión del docente en la dignidad humana desde la diversidad. De allí que, cada persona aprende y se desarrolla a su ritmo y etapa de vida.

En esa misma línea, surge el elemento Enseñanza desde el Ejemplo y el Amor en el desempeño del docente en el quehacer educativo prescribe en la actitud de brindar amor y ejemplo a los estudiantes en una praxis educativa amorosa para brindar un ambiente humano a los estudiantes, surge en ellos los valores y principios, desde el ejemplo se crean conductas para la consolidación de la formación de seres humanos en la dignidad y la participación de todos, igualmente los aprendizajes significativos en el proceso de enseñanza-aprendizaje, se facilitan a través de un contexto educativa, brindar amor no significa tolerar todo lo que realice los educandos, es dar un trato digno en comprender las realidades complejas que poseen los estudiantes, partiendo de allí brindarle un espacio diferente a su contexto personal. 
De acuerdo con lo anterior, es una actitud que subscribe la labor educativa desde la percepción del sentido educativo amoroso y ejemplarizante del educador en los estudiantes. Los anteriores elementos se convergen en las dimensiones que integran la Visión Hologógica del Docente en el contexto de Educación Primaria, concatenado con Hurtado (1998a): "desde una comprensión holística el ser humano se aproxima al conocimiento en un proceso permanente en espiral donde cada resultado alcanza grados de complejidad cada vez más avanzados" (pág. 127). Al respecto, el uso de la espiral holística en la investigación propuesta por Hurtado (1998b): "constituye un modelo que organiza y sistematiza la información y el conocimiento en metodología de investigación por medio de la metáfora de la espiral holística" (pág. 136).

Con referencia a lo anterior, en la estructura de la Visión Hologógica del Docente posee elementos que interactúan en las dimensiones que se develan en la concepción de los profesionales de la docencia. Es así, que la espiral holística se relaciona con la visión que emerge de los docentes, se estructura en Espirales Hológogicos, en que recorre los elementos de la praxis y perspectivas de los docentes en la medida que recorre cada elemento de forma infinita las dimensiones se consolidan, representado logros sucesivos en el desempeño del docente en la educación primaria para la transformación de la educación tradicional a la educación holística, adaptada a las exigencias del Siglo XXI.

\subsection{Dimensión Concepción Hologógica del Docente}

La concepción hologógica del docente se orienta en el humanismo, como corriente del pensamiento que reúne diversos enfoques que guardan relación en el postulado que el docente es el mediador de los procesos de enseñanza- aprendizaje, en el cual recae la acción educativa en el quehacer educativa desarrollar en los estudiantes la capacidad de curiosidad, 
creatividad, conocerse a sí mismo como seres humanos, consolidando las áreas cognitivas como afectiva en el marco de una educación holística que permita el crecimiento personal de los educando desde la praxis del docente, desde la perspectiva de los holos, el docente adquiere una posición holística ante las diversas complejas y diversas realidades, en que como seres humanos son ente creador, reflexivo y deliberado que se desempeña en el quehacer educativo adquiriendo experiencias y aprendizajes con los demás actores educativos.

Bajo las premisas anteriores, la docencia con enfoque humanista se vincula con la holística que promueve los valores sociales y dignidad humana en el quehacer educativo, en función de promover los holos de cada educando, reconociendo los principios básicos, la educación integral, desde y para los seres humanos, en este contexto, se humaniza el proceso de enseñanzaaprendizaje para consolidar la formación bajo una visión integradora. En efecto, Barrera (2013d), indica una visión sobre el proceso educativo desde la particularidad de una realidad integral que trasciende todas las posturas de los actores del contexto escolar:

La comprensión hologógica implica la visión de la personaprincipio, centro y fin de la educación, como una integridad, como una realidad, íntegra, integral y a su vez trascendente. A diferencia de las posturas antropológicas que fraccionan y atomizan la condición humana, la educación holística insiste en la necesidad de apreciar la persona en su totalidad, en su conjunto, desde la integralidad, como complejidad, pues apreciadas las cosas desde la totalidad se puede percibir con más precisión los detalles propios de su condición humana (pág. 54).

Es así, que quien se desempeña como docente, tiene un papel decisivo en la conformación de la personalidad de quienes están bajo su égida y, de su formación moral, de su ejemplo, de su intercambio de conocimientos y saberes hace de los educandos ciudadanos para el compromiso, responsabilidad, 
democracia y para el bien común de la comunidad desde un ser holista para la integralidad de las realidades actuales, basada en la concepción hologógica, desarrollando de forma espiral, como se ilustra en el espiral Hologógico, de la figura 2.

Figura 2. Espiral Hologógico: Dimensión Concepción Hologógica del Docente.

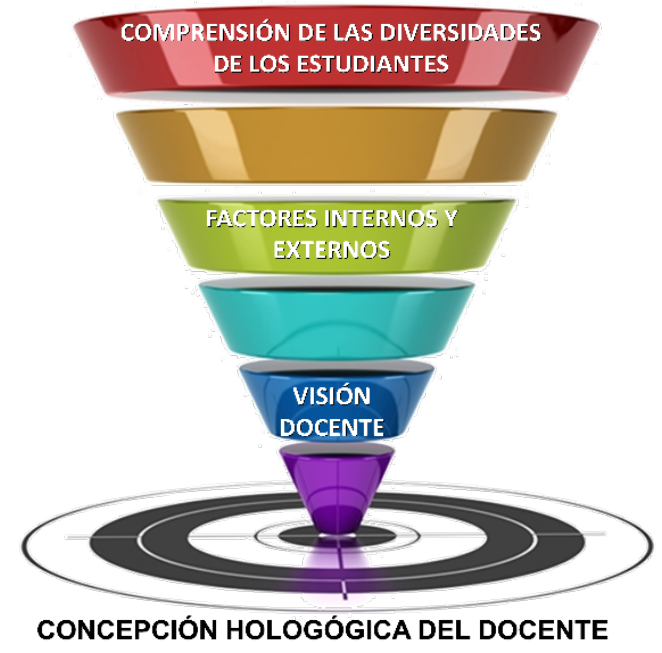

Fuente: El Autor (2019).

\subsection{Dimensión Vocación de Servicio}

La vocación de los docentes de educación primaria se hace visible todos los días cuando el docente recibe a sus estudiantes con una sonrisa y una abrazo, los niños, niñas y adolescentes expresan su cariño, aprecio y gratitud con sus profesores, de igual manera, en el aula las expresiones de colaboración, respeto, intercambio voluntario de todos los actores en el quehacer educativo, sin embargo, hay situaciones aisladas donde se muestra que algunos factores afectan la vocación de algunos docentes que se muestras desanimados y sin interés de desempeñar sus funciones.

En este contexto, es importante destacar que la vocación de servicio se orienta al sentimiento que posee en su hacer y deber como profesional de la docencia, en cuanto al nivel de interés, ánimo, compromiso. voluntad, 
tolerancia, comprensión, responsabilidad, amor, sensibilidad, amabilidad, respeto, empatía para cumplir con humanidad su desempeño como planificador de aprendizajes en seres humanos en su formación integral en el marco de la educación holística. En este mismo orden de ideas, desde la estructura de la Visión Hologógica del Docentes se hace necesario como indispensable la vocación como lo interno que impulsa, motiva y activa el deber ser en la labor educativa de los maestros, prevaleciendo la dignidad humana en el quehacer educativo, como se presenta en la figura 3.

Figura 3. Espiral Hologógico: Dimensión Vocación de Servicio.

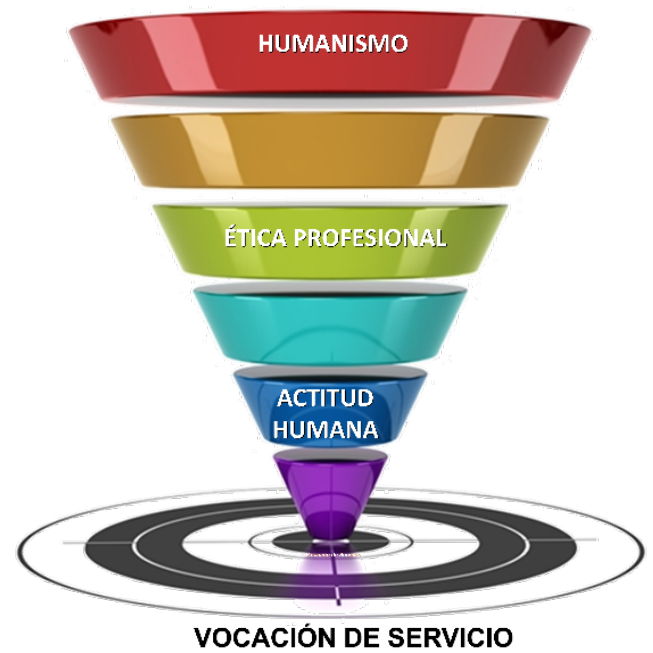

Fuente: El Autor (2019).

De allí que, Larrosa (2010), describe las condiciones del ejercicio de la profesión docente, tal como: "vocación (inclinación natural para dedicarse a la actividad profesional de enseñar con entusiasmo, compromiso y confianza en el poder de la educación, dedicación especial y de servicio hacia los demás)" (pág. 49). En base de las consideraciones anteriores, la Dimensión de Vocación de Servicio mediante el espiral Hologógico interactúa con los elementos de forma continua e infinita desarrollando en el los profesiones de la docencia una Vocación desde el amor y la holística del proceso de formación 
integral de los estudiantes en el contexto de educación primaria.

\subsection{Dimensión Praxis Docente}

La docencia en la educación primaria, admite que el humanismo es una corriente que centra su interés en lo humano, con la interpretación de los educamos en el proceso de enseñanza aprendizaje, para seres humanos, por lo cual la actuación del docente debe ir orientada en relaciones humanos en armonía, solidaridad, respeto, tolerancia y amorosa. Dentro de este contexto, la acción docente de los profesionales de la docencia se empeña en su labor educativa con conciencia, disposición, conocimientos, tolerancia, empatía, respeto y cumplimiento con las normas y reglamentes, sugerido de las relaciones docente-estudiante basados un trato más humano, impulsando la creatividad, valorando los seres humanos.

De modo que, la praxis del docente se orienta en una función que transciende la enseñanza de las letras, las matemáticas, las ciencias naturales o transferencia de un ámbito determinado del saber, por consiguiente, debe materializarse desde la comprensión de las realidades de cada estudiante en el desarrollo de sus capacidades y habilidades para la formación integral de ciudadanos y ciudadanos de la sociedad venezolana en el crecimiento personal.

Al respecto, Freire (1977): define "la educación como práctica de la libertad" (pág. 108); y por otra parte, Barrera (2013e), sostiene que: "atender el quehacer educativo desde una comprensión holista, integral, integrativa y universal, implica el acercamiento a una visión igualmente integrativa y holista del ser humano" (pág. 24). De los anteriores planteamientos, la praxis del profesional de la docencia en la visión hologógica se vincula con la acción pedagógica desde la enseñanza del amor, la comprensión holística de los estudiantes desde su integralidad, diversidad y complejidad con la postura de respeto de la dignidad humana, desde la diversidad de las capacidades de 
aprender de cada educando como seres humanos en formación, como se observa en la figura 4.

Figura 4. Espiral Hologógico: Dimensión Praxis Docente.

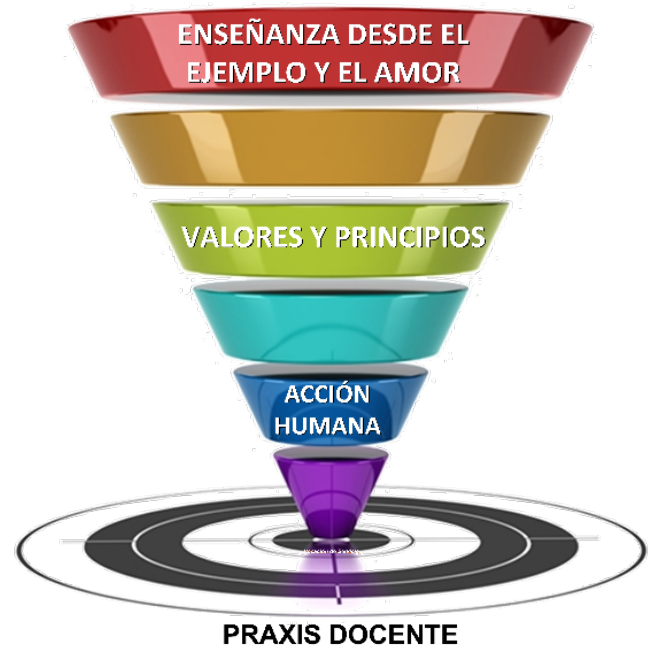

Fuente: El Autor (2019).

\subsection{Dimensión Formación Hologógica}

Desde la formación hologógica como el proceso de enseñanza y aprendizaje desde la concepción de la construcción e intercambio de saberes, conocimientos, habilidades y destrezas desde lo colectivo, identificando y valorando la integralidad, unicidad, el holos para una comprensión de la realidad social relacionada con las inquietudes, sentimientos, intereses y necesidades de los educandos, con la finalidad de asumir la misión del docentes desde una perspectiva de educar y formar en valores, moral y principios éticos como ciudadanos comprometidos y responsables de sus actos y relaciones con los demás en un constante actividad formativa en lo espiritual y cognitivo impulsando el aprendizaje significativo.

Hecha las consideraciones, se ubica la importancia de colocar a los estudiantes en el centro del hecho educativo, reconociendo que posee características únicas y que presenta un ritmo de aprendizaje personal que, 
en relación con otros, resulta un intercambio entre seres humanos que construyen de manera colectiva, los conocimientos y aprendizajes en una interacción con proceso educativo continuo, desde la complejidad de la realidad de todos actores del contexto educativo.

En este propósito, es importante que en la formación holística los docentes comprender la necesidad que reubicar el amor como centro de las acciones, estrategias que el profesional de la docente desarrollo en el quehacer educativo para la comprensión de las debilidades y necesidades de los estudiantes de la educación primaria, además, lo planteado por Barrera (2013f): "la hologogía reivindica el amor como condición necesaria, pues todo lo que inspira la actividad educativa tiene como propósito el bien, y el bien es amor" (pág. 76).

Dados los antecedentes, surge la importancia de la diversidad de los estudiantes como holos, que poseen diversas y complejas realidades, en función de una formación en base a la educación holística, identificando las necesidades e intereses que surgen las relaciones de los actores del hecho educativo, con el concurso de impulsar la creatividad y espiritualidad de los educandos, desde la premisa de la concepción de los docentes de educación primaria referida a desempeñar la visión del docente hologógica en su praxis educativa, con la comprensión y reflexión de las diversas realidades de los estudiantes, en relación con Gallegos (2001): "cada educador holista es una esperanza por una mejor humanidad" (pág. 75).

Cabe agregar, que la formación holística reside en la habilidad de los docentes en cuanto desarrolla la enseñanza en la medida que aprende, lo que postula que desempeñe su labor de formador desde su saber propio e impulse en el hecho educativo los conocimientos significativos y pertinentes desde la comprensión holística de los estudiantes para que exista un ambiente de armonía, amoroso, humano, espiritual en la construcción de los conocimientos y aprendizajes de la visión hologógica educativa, como se ve en la figura 5. 
Instituto Internacional de Investigación y Desarrollo Tecnológico Educativo INDTEC, C.A.

DOI: https://doi.org/10.29394/Scientific.issn.2542-2987.2020.5.16.14.269-289

OAI-PMH: http://www.indteca.com/ojs/index.php/Revista_Scientific/oai

Ensayo Original / Original Essay

Figura 5. Espiral Hologógico: Dimensión Formación Hologógica.

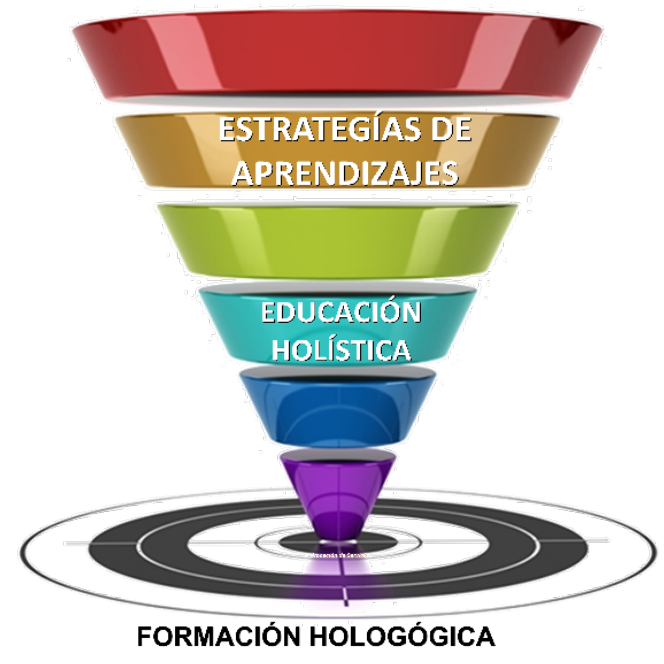

Fuente: El Autor (2019).

\section{Conclusiones}

A la luz del recorrido teórico, se analizó e interpretó la fundamentación epistémica y teoría concatenada con la concepción hologógica en los docentes de educación primaria, a través de las entrevistas a profundidad, detentando debilidades en cuanto a la praxis educativa y la relación entre los actores educativos del quehacer educativo, el proceso de enseñanza y aprendizaje, fomento de los valores y equipo de trabajo, la mediación y dialogo de saberes en la construcción del conocimiento, clima escolar, entendimiento de las necesidades, debilidades de los educandos, falta de amor y empatía en el proceso educativo.

Lo que surgió, en análisis e interpretación teórica los elementos de una concepción hologogica educativa en los ambientes de aprendizajes, tales como: Visión del Docente, se orienta a la percepción de los docentes en cuanto a su misión, visión en la labor educativa desde la perspectiva holística en el proceso de enseñanza y aprendizaje de los educandos; Comprensión de las diversidades de los estudiantes, se refiere a la valoración e 
interpretación de los docentes de educación primaria para proveer la acción educativa desde la diversidad de los estudiantes en formación en el marco de los principios de la hologogía.

En este orden de ideas, los Factores internos y externos del docente, hace referencia a el contacto social, cultural y político que se desarrolla en el país que afecta en la mayoría de los profesionales de la docencia y su desempeño en el contexto escolar, menoscabando las relaciones de docente y estudiantes, desde el surgimiento de barreras, limitaciones derivadas de los factores que influyen en el clima escolar, la Enseñanza desde el amor y el ejemplo, considera el principio elemental del proceso educativo el amor como marco de la acción de educativa de los docentes de las escuelas, en función de la comprensión que el educar es un actor para el amor a los seres humanos que se encuentran en proceso de formación, es el actuar del profesional de la docencia desde el amor y para el amor de los estudiantes.

Atendiendo estas consideraciones, el Humanismo: se manifiesta en la práctica educativa de los docentes en el contexto de educación primaria desde el humanismo, consideró como característica principal del hecho educativo la humanización del proceso educativo en todas sus fases y etapas, una educación humanista para seres humanos, donde prevalezca la dignidad humana, Actitud humana: Se relaciona con el comportamiento y el conjunto de actitudes humanas de parte de los docentes en el contexto de la educación primaria relacionado con las reacciones que presentan ante determinadas situaciones en la interacción con los estudiantes y el entorno escolar, Ética profesional: se concibe en la concepción de los docentes relacionado con el deber ser en su servicio como educadores, incluye los valores y principios éticos-morales, el amor al servicio, la dedicación, la responsabilidad y la satisfacción del deber cumplido.

Aspectos Cognitivos: Se integra con la concepción y praxis de los docentes en la educación, los aspectos cognitivos son elementos importantes 
para que surja un proceso educativo integral y holístico en el reconocimiento de la diversidad en la realidad compleja de los estudiantes en función del reconocimiento como seres humanos, en garantía de un hecho educativo humanista, espiritual con la generación de conocimientos de manera colectiva desde la individualidad. Estrategias de aprendizaje: se fundamenta desde la concepción integral de los profesionales de la docencia de la educación primaria fundamentada en la actitud positiva, dinámica y dedicada a la praxis educativa de enseñar aprendiendo de los estudiantes, reconociendo sus saberes, conocimientos y habilidades propias como seres humanos y por último de los elementos, la Educación Holística: se orienta en la importancia de colocar a los estudiantes en el centro del hecho educativo, reconociendo que posee características únicas y que presentan un ritmo de aprendizaje, concatenado con los espirales hologógicos como sustento de una educación espiritual y movimiento infinito.

\section{Referencias}

Barrera, M. (2013a,b,c,d,e,f). Hologogía: Introducción a la educación holística. Tercera edición. Caracas, Venezuela: Ediciones Quirón \& Sypal.

Freire, P (1993). Cartas a quien pretende enseñar. 2da edición, 3era reimpresión, Biblioteca Clásica del siglo veintiuno. Buenos Aires, Argentina: Siglo XXI Editores.

Freire, P. (1977). La Educación como práctica de la libertad. 3ra edición, 1ra reimpresión, Biblioteca Clásica del siglo veintiuno. Buenos Aires, Argentina: Siglo XXI Editores.

Gallegos, R. (2003). Pedagogía del Amor Universal. Una visión holista del mundo. Guadalajara, México: Editorial Fundación Internacional para la Educación Holista.

Gallegos, R. (2001). La educación del corazón. Doce principios para las 
escuelas holistas. Guadalajara, México: Editorial Fundación Internacional para la Educación Holista.

Huerta, J. (2008). Actitudes Humanas, Actitudes Sociales. Depósito Legal: M-2498-2008. Conferencia pronunciada por el Autor en la Universidad de Mayores Experiencia Recíproca, en el año 2007. Madrid, España: Universidad de Mayores de Experiencia Recíproca. Recuperado de: http://www.umer.es/wp-content/uploads/2015/05/n47.pdf

Hurtado, J. (1998a,b). Metodología de la Investigación Holística. ISBN: 9806306-06-6. Caracas, Venezuela: Fundación Sypal.

Larrosa, F. (2010). Vocación docente versus profesión docente en las organizaciones educativas. REIFOP: Revista Electrónica Interuniversitaria de Formación del Profesorado, 13(4), 43-51, e-ISSN: 1575-0965. Recuperado de:

https://dialnet.unirioja.es/servlet/articulo?codigo $=3675464$

Rojas, C. (2011). Ética profesional docente: Un compromiso pedagógico humanístico. Revista Humanidades: Revista de la Escuela de Estudios Generales, 1(1), 1-22, e-ISSN: 2215-3934. Recuperado de: https://dialnet.unirioja.es/servlet/articulo?codigo $=4920530$ 


\section{César Enrique López Arrillaga}

e-mail: prof.cesarlopez@gmail.com

Natural de La Guaira, estado La Guaria, Venezuela, nacido

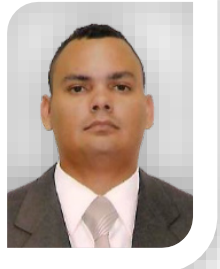
el 7 de mayo del año 1985. Doctor en Ciencias de la Educación, Universidad Latinoamericana y del Caribe (ULAC); Magister Scientiarum en Educación Superior de la Universidad Nacional Experimental Politécnica de la Fuerza Armada Bolivariana (UNEFA); Licenciado en Educación de la Universidad Nacional Experimental Simón Rodríguez (UNESR); Comisionado Municipal de la Oficina Antidrogas del municipio Independencia; Director de Recursos Humanos de la Alcaldía del municipio Independencia; Jefe de Personal de la Policía Municipal Independencia; Director de Administración, Finanzas y Presupuesto de la Contraloría del municipio Simón Bolívar; Tutor de Trabajos Especiales de Grado (Especializaciones y Maestrías) en la Universidad Pedagógica Experimental Libertador (UPEL) y la Universidad Nacional Experimental Politécnica de la Fuerza Armada Bolivariana (UNEFA); Coordinador de Control de Estudios de la Unidad Educativa Privada Coronel Antonio Nicolas Briceño; Actualmente docente de Educación Primaria de la Unidad Educativa Nacional Bolivariana Guaicaipuro; Arbitro Calificado y Comité Académico Científico de la Revista Scientific (e-ISSN: 2542-2987); Arbitro de la Revista Ensayos Pedagógicos (eISSN: 2215-3330), de la División de Educología del Centro de Investigación y Docencia en Educación (CIDE), Costa Rica y Revista Pedagogía y Saberes (e-ISSN: 2500-6436) de la Facultad de Educación de la Universidad Pedagógica Nacional (UPN), Colombia.

El contenido de este manuscrito se difunde bajo una Licencia de Creative Commons ReconocimientoNoComercial-Compartirlgual 4.0 Internacional 